\title{
DERECHOEIECTORAL
}

\section{Las tensiones de la paridad electoral sobre diversidades sexuales no binarias}

\author{
José Mario Achoy Sánchez* \\ https://doi.org/10.35242/RDE_2020_30_8
}

\section{Nota del Consejo Editorial}

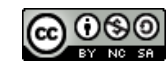

Recepción: 31 de mayo de 2020.

Revisión, corrección y aprobación: 6 de julio de 2020.

Resumen: La reivindicación de espacios y derechos de las mujeres en los escenarios políticos se ha materializado por medio de narrativas de opinión pública, enlazadas a través de importantes reformas para garantizar una cuota de paridad en materia de elección popular. Empero, esta acción mediática con visión binaria (masculino-femenino) implica que, para los puestos con reglas de paridad, no se haya previsto que una persona con una identidad de género autopercibida distinta al carácter dicotómico, acceda a mecanismos de elección sin que la alternancia dualista limite y discrimine, en razón de que su identidad de género no encaje en tal dicotomía. Es un fenómeno de narrativa inclusiva con implicaciones prácticas de exclusión por la identidad sexual de una persona, por ejemplo, las personas lesbianas, gays, bisexuales y transgénero pueden llegar a identificarse con la palabra queer o las personas que nacen con caracteres sexuales como los genitales, las gónadas y los patrones cromosómicos, denominadas intersexuales o intersex.

Palabras clave: Paridad política / Cuotas de participación política / Equidad de género / Identidad de género / Identidad de género / Población LGTBI.

Abstract: The vindication of rights and spaces for women in political scenarios has been materialized through public opinion narratives and reforms to guarantee a parity quota in terms of popular election matters. However, this mediatic process with a binary vision (masculine-feminine) implies that, for positions with parity rules, it is not foreseen that a person with a self-perceived gender identity different from the dichotomous character can access election mechanisms without having the dualistic alternation limit and discriminate because its gender identity does not fit in such dichotomy. It is a phenomenon of inclusive narrative with practical implications of exclusion for a person's sexual identity (queer, intersex, for example).

Key Words: Political parity / Political participation quotas / Gender equity / Gender identity / LGTBI population.

\footnotetext{
* Costarricense, abogado, correo jmachoys@gmail.com. Licenciado en Derecho por la Universidad de Costa Rica y estudiante del bachillerato y la maestría académica en Ciencias Políticas por la misma Universidad. Con formación técnica en prácticas democráticas y procesos electorales por la Universidad Estatal a Distancia, así como estudios en Derecho, Política y Sociedad por la Universidad de Berlín y la Universidad Johann-Wolfgang Goethe de Frankfurt. Actualmente consultor para el Programa Estado de la Nación y asistente legal para la Universidad de Costa Rica.
} 


\section{DERECHO EIECTORAL}

\section{INTRODUCCIÓN}

Para Irving Crespi (1997), la opinión colectiva se construye no solo a partir de interacciones y relaciones entre individuos; sino, también, con motivo de procesos de comunicación social compleja que reflejan diferentes dimensiones de los colectivos "utilizando un universo discursivo común" (p. 86). No obstante, ¿qué sucede cuando tal panorama narrativo excluye tácitamente a personas del mismo cuerpo social?, ¿es intencional y como resultado de un disenso? ¿Acaso nunca se estimó, tan siquiera, su inclusión dentro de ciertos procesos como lo político?, ¿qué sucede cuando, dentro de una visión binaria, nunca se pensó sobre la posibilidad de una realidad social no-dicotómica?

Con el devenir de la participación femenina en el espacio político, primero a través del voto $y$, posteriormente, por medio de su habilitación en candidaturas, han surgido instrumentos internacionales, leyes internas, narrativas discursivas y estrategias de campaña para reivindicar, justamente y con merecido esfuerzo por sus luchas, aquellos espacios políticos en los que históricamente había sido negada su participación. Lo anterior, con motivo de la trayectoria electoral que, bajo una visión construida por patriarcas, les negaron desproporcionadamente e injustamente los derechos políticos a las mujeres y su influencia en el ámbito de lo público.

La narrativa feminista es tan transversal e interseccional ${ }^{1}$ como diversa e integral. En el caso de lo político, el discurso se ha reforzado para ocuparse de espacios donde antes había estado oculto por medidas opresoras desde el poder institucional, pasando por las prácticas mercantilistas del capitalismo y hasta en las complejas redes de comunicación social. Hoy en día, aunque todavía de manera insuficiente, la mirada y perspectiva feminista en este ámbito ha permitido que una niña pueda imaginar, al menos, la posibilidad de que su futuro tendrá

\footnotetext{
1 El concepto de transversalidad de género es definido por el Consejo Económico y Social de las Naciones Unidas en 1997como:

El proceso de valoración de las implicaciones de hombres y mujeres en cualquier acción planeada, incluyendo la legislación, políticas y programas en todas las áreas y niveles. Es una estrategia (...), una dimensión integral del diseño de políticas y programas en todas las esferas, política, económica y social, de modo que ambos géneros se beneficien igualitariamente (PNUD, 2006, p. 17).

La interseccionalidad es: "una propuesta iniciada por las teorías feministas de los años setenta, resulta esencial para analizar los diversos tipos de opresión por los que cualquier individuo se enfrenta, no solo según su sexo/género, sino también según otras razones (raza, clase, lengua, cultura, sexualidad, procedencia, edad, discapacidad, etc.)" Hernández, 2018, p. 281).
} 


\section{DERECHO ELECTORAL}

ventanas donde no le será negado el derecho a votar o a ser parte de una papeleta para una elección popular.

Con el pasar de las últimas décadas, todavía queda muchísimo camino por recorrer en el proceso de reivindicación social de los derechos de las mujeres; sin embargo, se ha consolidado un fuerte argumento en el universo discursivo común de las sociedades modernas, que ha permitido consensuar desde estructuras de poder como la Organización de Estados Americanos (OEA), colectivos universitarios, comunales o sociales, la promoción de medidas y políticas sobre la inclusión de la cuota paritaria en los procesos de elección popular.

Por ejemplo, la Convención Belem do Pará, suscrita para erradicar la violencia en perjuicio de las mujeres, obliga a todos los Estados parte a tomar medidas legislativas y administrativas para garantizar los derechos de esta población históricamente desplazada en circunscripciones como la participación política. De ahí que muchos países han llevado el tema hasta las urnas, lo han incorporado en debates legislativos, se ha empujado frecuentemente en discusiones de inclusión social y de género, e inclusive, se ha mediatizado hasta polarizar a la población con el fin de influir en resultados en el poder político, entre otras cosas. Sin embargo, existe un aspecto que nadie discute (por ahora): la paridad electoral y los mecanismos de alternancia para garantizar cuotas específicas de participación a las mujeres versan sobre un asunto sexualmente dicotómico y binario, masculino y femenino. Diferente a lo que la narrativa discursiva de la equidad implica, esto excluye todo aquello que no se encuentre en ese paréntesis dualista.

Lo que no se cuenta ni se menciona no existe: lo que procede de las imágenes simplificadas de la realidad es la realidad tal como la experimenta la gente (Neumann, 1995). Si se concentra a la masa electoral en un universo discursivo bipolar (masculino-femenino), ¿qué sucede con los miembros del propio colectivo cuyos géneros no se identifican en una de estas posturas dicotómicas? La realidad narrativa y el mencionado universo discursivo están ambos asentados sobre una base de consenso que implica, necesaria e indiscutiblemente, que la cancha de juego, la imagen simplificada vuelta realidad, es una realidad binaria; empero, por más inclusivo que ha sido el tema en aspectos mediáticos, esto también ha devenido, tácitamente, en desplazar a poblaciones respecto de los derechos políticos que han sido reclamados. 


\section{DERECHO ELECTORAL}

\section{El CASO de AmÉRICA LATina}

A lo largo de la segunda mitad del siglo pasado y las últimas dos décadas, la región latinoamericana se ha visto expuesta a procesos reformistas y de cambio estructural en sus bases políticas. Pese a tratarse de un asunto instintivamente inclusivo, el reconocimiento del sufragio para las mujeres y su participación en candidaturas políticas ha significado el avance en un camino que, todavía, no se ve por acabar. Social y culturalmente, las prácticas patriarcales aún se encuentran impregnadas en el alma de algunas masas para la población latinoamericana y siguen difundiéndose volátilmente en los ojos de la opinión pública. Desde otra perspectiva, se encuentran los avances en materia de género y diversidad sexual que también han requerido un ajuste estructural en las narrativas de Gobiernos, campañas electorales y medios de información, con el fin de adecuar las exigencias contemporáneas en temas de reconocimiento e inclusión. Este caso es muy particular: no solo afronta, también, las imposiciones discursivas de sociedades machistas y conservadoras; sino que se posiciona mediante la incorporación de agendas discursivas de compleja difusión y que se vinculan con más arraigo (pero no únicamente) a la condición etaria de la población. Como parte de los hechos históricos que han sucedido en este campo, desde enero de 2018, la Corte Interamericana de Derechos Humanos sostiene, en cuanto a identidad de género autopercibida, lo siguiente:

\section{Los Estados cuentan con la posibilidad de establecer y decidir sobre el procedimiento más adecuado de conformidad con las características propias de cada contexto y de su derecho interno, los trámites o procedimientos para el cambio de nombre, adecuación de la imagen y rectificación de la referencia al sexo o género, en los registros $y$ en los documentos de identidad para que sean acordes con la identidad de género auto-percibida, independientemente de su naturaleza jurisdiccional o materialmente administrativa, deben cumplir con los requisitos señalados en esta opinión. [El resaltado es propio]. (Corte IDH, 2018, p. 69).}

A partir del citado texto, los países de América Latina que reconocen a la Corte IDH empezaron a contar con la presión mediática de una narrativa global y de tendencia, así como con la obligación de cumplimiento por motivo de una sentencia de este tribunal interamericano: los temas de 


\section{DERECHO EIECTORAL}

diversidad y el ajuste estructural sobre la identidad de género autopercibida es una circunstancia que se debe reconocer para todos los efectos políticos, administrativos o institucionales y mediáticos. Según sea el ordenamiento interno de cada país, este pronunciamiento inclusive puede ser de acatamiento obligatorio para los Estados que así lo hayan contemplado en sus jurisdicciones.

A partir de los procesos y movimientos sociales que han resultado en el justo reconocimiento de espacios para grupos minoritarios, algunos países de la región han impulsado agendas legislativas para garantizar la participación política de las mujeres y también se han lanzado al discurso inclusivo en cuanto a reconocimiento de identidad de género autopercibida para la población. En ese sentido y con motivo de la presente ponencia, se estudió en profundidad la situación de la paridad y los mecanismos de alternancia electoral para veinte países de América Latina, de forma que se incluyeron aquellos con, al menos, una disposición específica sobre cuotas de participación electoral y procedimientos de alternancia en puestos elección popular, como se aprecia en la Figura 1.

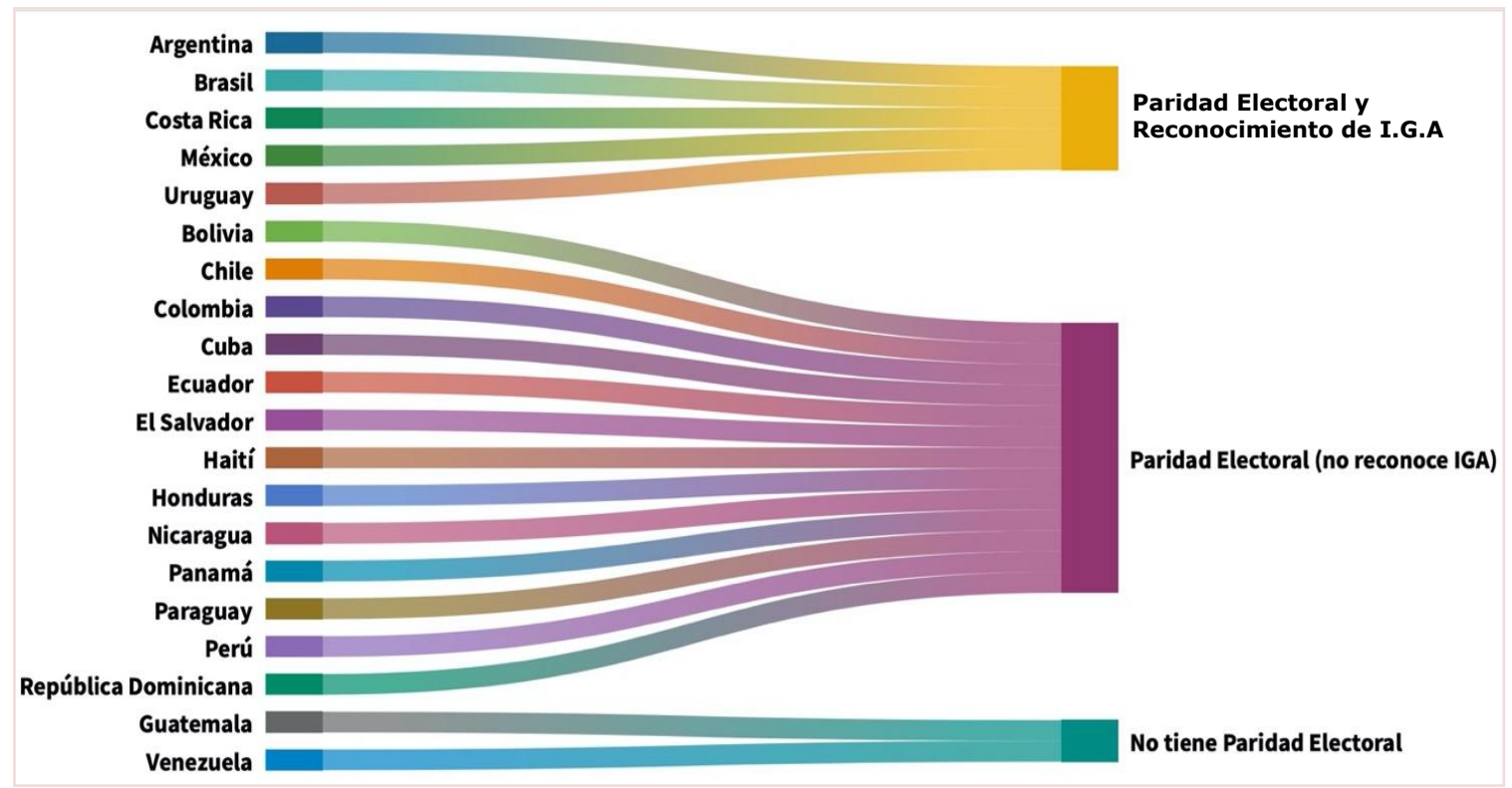

Figura 1. Grafico de distribución de países latinoamericanos según mecanismos de paridad o alternancia electoral y reconocimiento de identidad de género autopercibida, $2019 . \mathrm{El}$ reconocimiento de identidad de género autopercibida se basó en aquellos casos donde los efectos civiles y legales se vinculan con el ejercicio de los derechos políticos como el sufragio. IGA: reconocimiento institucional de la identidad de género autopercibida. Elaborado con base en Leyva, O. et al (2018). 


\section{DERECHO ELECTORAL}

Con base en los datos anteriores, del objeto estudiado (veinte países de la región), únicamente el $25 \%$ de ellos cuenta con mecanismos administrativos, civiles o políticos para reconocer la identidad de género autopercibida en el ámbito de los procesos electorales y, a su vez, exigen paridad en las nóminas de postulación para cargos de elección popular; es decir, en cinco países existe la posibilidad de que, frente a un comicio electoral, el Estado reconozca la identidad de género autopercibida de una persona queer o intersex, por ejemplo. Sin embargo, al momento en que tal persona se postule a un puesto de elección popular, entra el conflicto de la narrativa: entre aquello a lo que el universo discursivo sostiene como género y aquello que institucionalmente solo se reconoce como sexo para efectos de postulación.

Para estos cinco casos, una persona que no se identifique dentro del dualismo narrativo sobre lo masculino-femenino tiene una imposibilidad para consolidar su candidatura en un proceso electoral; toda vez que la obligatoriedad legal de listas con alternancia dicotómica y construidas bajo el criterio legal del sexo registrado al nacer impide el acceso a la elección para aquellas personas a quienes el propio Estado reconoció civilmente su género fuera de tal carácter binario, pero que no calzan en la narrativa institucionalizada de lo que se ha consensuado ante la opinión pública como paridad.

Al ni siquiera reconocer la identidad de género autopercibida, el 75\% restante de los países aún no vislumbra la posibilidad real para que una persona con un género distinto al femenino 0 al masculino sea institucionalmente reconocida como tal para efectos electorales. Es decir, tampoco podría, eventualmente, pensarse en la posibilidad de que una persona transgénero ${ }^{2}$ (decididamente incorporada al componente de lo binario) se postule según esa identidad. De tal suerte, el discurso de lo mediático y lo institucionalmente arraigado discrimina y desplaza a esta población, dado que la obliga a encasillarse de forma exclusiva a lo que se ha convenido en el plano de lo social bajo la estructura conservadora.

En un $85 \%$ de los veinte países, la "equidad" de postulación electoral es una realidad: sea para cargos legislativos, municipales o nacionales, los organismos de administración electoral exigen al menos una modalidad (vertical/horizontal) de paridad o un sistema de cuotas de participación

\footnotetext{
${ }^{2}$ Personas que sienten que el sexo asignado al nacer no coincide con su identidad de género.
} 


\section{DERECHO ELECTORAL}

que deben ser designadas de manera exclusiva a la población de sexo femenino.

Aún cuando esto se oferta como una política pública de inclusión y equidad, lo cierto es que, para todos estos casos, la narrativa con promesa democrática en realidad excluye a aquellas personas que, en el universo discursivo, deben entrar a una camisa de fuerza para identificarse según su sexo y no según su género: "la observación de los hechos está filtrada incluso moralmente por puntos de vista selectivos, puntos de vista guiados por estereotipos o códices" (Neumann, 1995, p. 205). Aunque los ojos de la opinión pública intenten reflejar discursos progresistas, la esencia de su visión está limitada por códigos exclusivos y que expulsan a todo aquello que no encaje bajo su programación social.

Sin embargo, cabe cuestionarse ¿por qué se consume tanto este producto mediático [la paridad], si tiene un vicio de razonamiento que genera exclusión social, política y discursiva? Es decir, ¿por qué se genera la narrativa de un asunto mediáticamente inclusivo, pero pragmáticamente excluyente? ¿Es acaso una narrativa que nació para excluir? ¿O nunca se imaginaron las posibilidades venideras de sus efectos discursivos?

Antes de entrar al fondo, cabe rememorar que las olas reformistas para establecer sistemas de elección popular más equitativos e igualitarios han sido, también, ofertadas por los grupos gubernamentales y de poder como una manera de consolidar sus aspiraciones. Pese a que versa sobre la reivindicación de derechos y no se puede desconocer el esfuerzo incansable de las fuerzas sociales por asegurar un espacio con voz y voto dentro de muchos boys clubs o espacios institucionales donde predomina la presencia de hombres y cuyas prácticas y decisiones se dirigen a opacar la labor de las mujeres; lo cierto es que este fenómeno, como proceso mediático, lamentablemente no ha estado exento de ser moneda de cambio en negociaciones partidarias o campañas electorales.

Además, el matiz patriarcal aún cosifica al género femenino en cuanto a materia de participación política: en muchos casos, la narrativa de inclusión no pasa más allá de situar en los puestos mejor garantizados (en términos de caudal político) a los hombres, con el fin de "rellenar" las posiciones legalmente exigidas mediante la inclusión de mujeres; aunque ello signifique su desplazamiento fáctico de las posibilidades reales de elección. 


\section{DERECHO ELECTORAL}

Esto quiere decir que también la participación política de las mujeres ha sido objeto de un proceso mediático dentro del universo discursivo de la sociedad civil en las diferentes regiones de América Latina, a tal punto en que este tema, en grados y aristas diferentes, ya resulta indiscutible cuando de consenso político se trata:

La medida de lo que en todas partes se llama y se considera virtud y vicio es esta aprobación o desagrado, alabanza o condena, que se establece por un consenso secreto y tácito en las distintas sociedades del mundo y por las que distintas acciones suscitan crédito o reprobación de acuerdo con el juicio, los principios o las modas del lugar (Locke citado por Neumann, 1995, p. 98)

Por ello, la evolución como especie humana ha conllevado que el discurso del poder y las narrativas de exclusión tomen ventaja a partir de los procesos biológicos de los otros individuos para perpetuar sus intereses de subsistencia. En ese sentido, existe un enfoque transversal de dominación, porque atraviesa esferas cotidianas como las referidas por Held (1997): a) salud física y emocional, b) dominio de bienes y servicios, c) cultura y vida social, d) asociaciones cívicas, e) economía, f) violencia y relaciones coercitivas y $\mathrm{g}$ ) instituciones regulatorias y legales. Pero también tiene un enfoque de transversalidad vertical, porque jerarquiza, a partir de los rasgos sociobiológicamente construidos para los individuos (como el género), el aporte utilitario que cada uno puede otorgar al sistema, de manera que van quedando rezagados y excluidos aquellos que del todo no sean de interés para la agenda programática del centro de poder.

\section{ILUSIONISMO DISCURSIVO EN LA DEMOCRACIA}

Durante las últimas 2 décadas, las naciones de América Latina han impulsado reformas legislativas para adaptar sus ordenamientos hacia las tendencias globales y las exigencias locales de participación electoral para las mujeres. En la mayoría de las ocasiones, este tema versa sobre un proceso narrativo que se lleva en campaña y que luego se plasma a través de políticas emanadas por los organismos electorales o, en su defecto, por mandato de los congresos, según sea el caso.

Sin embargo, la idea de promover una mayor equidad e inclusión en los procesos relacionados con el sufragio no precisamente responde a un 


\section{DERECHO ELECTORAL}

razonamiento coherente de habilitar espacios políticos a la mayor diversidad de la población democrática. A esto se le podría establecer, para efectos de la presente ponencia, como la promesa o ilusión discursiva de la democracia.; la cual consiste, básicamente, en que el universo discursivo es manejado o manipulado en narrativas electorales para fijar u obtener un resultado determinado; sin embargo, este proceso consigue como "fruto" aquello que la masa, el cuerpo electoral y político, y la sociedad desean, aunque en el fondo sea contradictorio con los principios $\mathrm{y}$ argumentos que motivaron su trayectoria procedimental.

En el caso de la "equidad y la igualdad de género", los colectivos feministas, los partidos políticos y la sociedad civil exigen y demandan constantemente la adopción de medidas legislativas, políticas, judiciales y administrativas que permitan reivindicar espacios para las mujeres; todo lo anterior, sin percatarse de que el universo discursivo en el que semantiza esa narrativa de "inclusión" tiene serios vicios de razonamiento, debido a que la base argumentativa de la narrativa parte de una premisa que asume como única posibilidad el dualismo sexual.

Es decir, los cimientos de tal universo discursivo se construyen a partir de narrativas (con o sin conciencia social) basadas en el espíritu y la utopía de hacer partícipes en la democracia a la mayor diversidad de personas; sin embargo, la cancha de juego desde la que se lleva a cabo tal proceso es naturalmente excluyente, pues parte del supuesto de que la paridad, la alternancia o la cuota solo son asuntos que pueden ser repartidos entre aquellas personas que se sometan a la dicotomía de lo masculino o lo femenino.

Es un ilusionismo: porque a pesar de que emite una narrativa de inclusión, equidad e igualdad, lo cierto es que solo se basa en una fórmula vacía que hace pasar una de las prácticas de exclusión social como la única existente, para justificar el diseño discursivo de todo el sistema electoral. Es decir, aún y cuando se incentiva como una estructura para garantizar la participación en procesos electorales de la forma más democrática posible con alusiones a la igualdad de género, se comete un error al inferir que la propiedad o condición biológica dualista (femenino-masculino) es también el esquema universal para aquellas personas con una identidad de género distinta.

En sentido estricto, es una promesa democrática que nace sin posibilidades de ser materializada, pero que de igual manera se narra y emite como discurso, aunque en el fondo esté normativa y políticamente 


\section{DERECHO EIECTORAL}

mal construida. No se puede reconocer la identidad de género bajo una lógica donde la opinión pública únicamente ha cristalizado en el sistema electoral la posibilidad de candidatura para mujeres y hombres; toda vez que se contradice, tácitamente, al excluir a todas las personas que -a través de los mecanismos facilitados por el propio Estado- tuvieron la posibilidad de reconocer su identidad no binaria, pero que serían excluidas de una lista de alternancia por no encasillarse dentro de las posibilidades dicotómicas de tal universo consenseual.

Es discursivo: porque nunca la narrativa de la igualdad de género en la participación electoral jamás fue razonada en términos de motivación semántica, sino que obedeció a un proceso sociohistórico de inequidad binaria:

Los razonamientos inferiores de las masas, al igual que los elevados, se basan en asociaciones; pero las ideas asociadas por las masas no mantienen entre sí más que vínculos aparentes de semejanza o sucesión(...). Las características de la lógica colectiva son la asociación de cosas dispares que no tienen entre sí otra cosa que las relaciones aparentes y la inmediata generalización de casos particulares.

Únicamente tales asociaciones pueden influir sobre las masas; para ellas, una concatenación de razonamientos rigurosos resultaría totalmente incomprensible, y por ello cabe decir que no razonan 0 que lo hacen erróneamente, no siendo influenciables mediante un razonamiento (LeBon, 2004, p. 32).

Cuando se habla de la paridad o la alternancia como el producto de un proceso reivindicatorio en espacios políticos, las propias masas están incurriendo en el error de razonamiento que se expuso en el punto anterior sobre el carácter ilusorio. Si a la narrativa de igualdad de género se le hubiere agregado el componente de las $n$ posibilidades que una persona podría tener en cuanto a identidad autopercibida, el universo discursivo habría sido incapaz de comprender al género bajo una visión disruptiva de lo que el dualismo sexual de lo femenino y lo masculino significa.

Es decir, los movimientos y fuerzas sociales que convergieron para consolidar y materializar en términos institucionales la igualdad de género con respecto a la participación política y las posibilidades de elección popular decididamente asumieron una posición que excluye a todo aquello 


\section{DERECHO EIECTORAL}

que no se encontrara cobijado por el carácter binario de la identidad sexual al nacer. "De este modo, la acción colectiva de los movimientos sociales, en sus diferentes formas, pretende introducir nuevas instrucciones y códigos en los programas de las redes" (Castells, 2009, pp. 78-79).

Es por esto que el consenso de tal espectro narrativo surgió siendo discriminatorio y se codificó de esa manera, pues de lo contrario su potabilidad estaba en riesgo: la operacionalización de la paridad o el sistema de cuotas solamente fue pensado para una lógica donde deben existir únicamente dos posibilidades de sujeto distintivo. En el caso concreto y según lo expuesto por LeBon (2004), lo que sucede no es otra cosa más que la confusión o aplicación erróneamente analógica, por parte de las masas, del término sexo con respecto al término género; de no haberse efectuado tal relación mental aparente, la masa habría sido incapaz de ser influenciable, pero solamente bajo tal razonamiento, la igualdad de género (contemplando las posibilidades no binarias) habría sido efectiva, coherente y hasta consecuente en el caso del $25 \%$ de los países que reconocen la identidad de género autopercibida:

El gobernante moderno se enfrenta a nuevos desafíos. El primero es el poder dotar a las organizaciones públicas de una nueva dimensión social capaz de retroalimentarse en tiempo real a partir del interés y las ideas que aporten diferentes colectivos. Ya no alcanza con la presunción o la sensibilidad para interpretar a la sociedad, porque esta se fracciona y se expresa a través de una multiplicidad de grupos que necesariamente expresan reclamos y expectativas diferentes. (Riorda et al., 2015, p. 7).

En este plano más que en cualquier otro, el contexto de la comunicación social y las dinámicas de poder se vería absolutamente expuesto. Ofrecer mediáticamente el producto de la igualdad de género para efectos de las elecciones populares, contemplando las diferencias que trascienden el carácter dicotómico, no solo sería poco eficiente en términos de narrativa -pues se habría tenido que dar una explicación incompresible para muchos tomadores de decisión-; sino que, a su vez, satisface las exigencias del descontento para la opinión pública, de manera que también resultaba ser un aspecto de sencilla resolución, aunque contradictorio en términos semánticos y discursivos. 


\section{DERECHOELECTORAL}

\section{SOBRE LA DEMOCRACIA}

En el caso concreto se trata de derechos fundamentales en cuanto al reconocimiento jurídico de la personalidad y el ejercicio efectivo de la participación política; sin embargo, en el imaginario colectivo la igualdad de género se comercializa en campañas bajo el argumento narrativo de democratizar la política y el sistema estatal. Al respecto, Crespi sostiene:

El reto de una democracia es la forma de organizar una comunidad política en la que los líderes que compiten y las organizaciones definan las alternativas de la acción pública de tal forma que el público pueda participar en el proceso de la toma de decisiones. Conseguir esto requiere, sobre todo, seleccionar a los líderes políticos de acuerdo con los procedimientos democráticos establecidos. (Crespi, p. 187).

Existe un entramado institucional mediante organismos y entes públicos que se encargan de llevar a cabo elecciones; medios de comunicación que fungen como plataformas de difusión y persuasión del poder; movimientos sociales y colectivos que se mueven de un lado a otro para decidir por las vías procedimentales su designio; empero, qué sucede cuando, a través de los canales burocráticamente establecidos, todos estos factores se conjugan para excluir de manera institucionalizada la participación de otros miembros de la comunidad.

Para el caso bajo estudio, la imposibilidad de permitir a una persona con identidad de género autopercibida diferente al carácter binario de lo masculino/femenino limita las posibilidades de ejercer efectivamente su derecho de postulación a cargos públicos cuando el propio sistema "democrático" le impone una alternancia paritaria en la que no se encasilla.

Lo contradictorio del tema es que el mismo entramado institucional le ha reconocido previamente su identidad de género queer o intersex; empero, para los efectos de postulación, en el $25 \%$ de los países bajo estudio estas personas tendrían que obligarse a encajar sobre la dicotomía femeninomasculino si quisieran optar por una candidatura en la que se exija paridad o cuota.

Si se excluye de la participación y la incidencia política en decisiones de alta importancia a este tipo de minorías, es posible concluir que la idea 


\section{DERECHO EIECTORAL}

democrática únicamente es un universo discursivo placentero para aquellos que lo conforman:

Sean cuales fueren los individuos que la componen, por similares distintos que puedan ser su género de vida, ocupaciones carácter o inteligencia, el simple hecho de que se hayan transformado en masa les dota de una especie de alma colectiva. Esta alma les hace sentir, pensar y actuar de un modo distinto de cómo lo haría cada uno de ellos por separado (...).

Esta puesta en común de cualidades corrientes nos explica por qué las masas no pueden realizar actos que exigen una elevada inteligencia. Las masas no acumulan la inteligencia, sino la mediocridad (LeBon, 2005, p. 29, 31).

En el ejercicio de transformar las narrativas sobre la igualdad desde la opinión pública y canalizarlas hacia su materialización política en el plano del poder, los movimientos sociales y las minorías que tanto defienden su motivación acaban en el sesgo discursivo de excluir, desde la democracia, a otras minorías. De ahí que la paridad y los intentos de igualdad de género en términos de elección popular resulta en un mecanismo que, a su vez, discrimina en razón de un criterio biológico (masculino, femenino), desde plataformas institucionales que inclusive han reconocido términos construidos desde lo sociológico (queer, intersex).

De ahí que no solo el discurso se convierte en contradictorio; sino que, también se contradice el espíritu de aquellos movimientos y fuerzas sociales que, antes de haberse incorporado a los planos de poder en la democracia, reclamaban un trato paritario sin exclusiones ni discriminación. No solo es incoherente el mensaje o el discurso, sino también el emisor.

\section{El caso de Costa Rica}

En el marco del proceso electoral para elegir a las nuevas autoridades municipales en el 2020, el Tribunal Supremo de Elecciones de este país conoció en instancia de apelación el recurso contra un acto en el que se impugnó un proceso de inscripción de candidaturas debido a inconsistencias procedimentales en las listas que proporcionó la agrupación política. En síntesis, el escenario apelado consistió en que se 


\section{DERECHO ELECTORAL}

admitiera como válida una nómina compuesta por una persona cuya identidad de género no era idéntica a la que fue registralmente asignada (según su sexo al nacer) $y$, en consecuencia, para una lista de candidaturas existía una postulación consecutiva de 2 personas con el mismo sexo.

Cabe mencionar que en el caso de este país, la misma institución de cita asumió las disposiciones emitidas en la OC-24/17 en cuanto a identidad de género para población sexualmente diversa: se realiza un trámite administrativo expedito para que aquellas personas con una autopercepción de género distinta a la de su sexo biológico puedan llevar a cabo el cambio sin mayor dilación ni obstáculo; sin embargo, también para esta República, el Código Electoral exige una paridad vertical para presentar candidaturas en puestos de elección municipal con base en el rasgo biológico del sexo registrado al nacer.

Concretamente, este organismo señaló:

Las pautas jurídicas en esta temática se concibieron para lograr que hombres y mujeres, calificados así por su sexo asignado al nacer, aspiraran, en igualdad de condiciones, a ocupar puestos públicos de toma de decisiones. Si las mujeres eran sujetas cuya participación política era negada en razón de una visión societal imperante que las infravaloraba, evidentemente la aceptación de otras orientaciones sexuales e identidades era imposible porque ni siquiera era pensada (...).

El tabú que implicaba lo sexualmente diverso negaba de los espacios de reconocimiento de derechos a quienes formaban parte de esos grupos. Es claro que esa posibilidad de generar políticas públicas en beneficio de grupos específicos también alcanza a las poblaciones sexualmente diversas; no obstante, la armonización que, en ese campo, corresponde hacer en temas como la participación equitativa basada en una trama social integrada por sujetos con identidades que no son polares (citado esquema dicotómico hombremujer) corresponde al legislador(...).

Así, al haberse pensado la paridad como una forma de solventar las asimetrías de participación entre hombres y mujeres (se insiste en la concepción biológica de esos 


\section{DERECHO ELECTORAL}

\section{términos) no es dable hacer una interpretación extensiva.}

De procederse de esa forma, se podría crear, en la práctica, un régimen de postulación de doble cuota (por ejemplo) o de otra naturaleza, suplantándose indebidamente al legislador en su competencia para diseñar los mecanismos de postulación y la construcción de las nóminas (...).

Tómese en consideración, además, que tales modificaciones requieren de la necesaria intervención del legislador, en tanto deben incorporarse variables como los indiscutibles derechos de personas intersex e incluso preverse escenarios en los que deseen postularse ciudadanos que no se entienden parte de ninguna de las categorías existentes (queer).

Por ejemplo, con base en la redacción actual del artículo 2 del Código Electoral, no sería posible determinar qué sexo correspondería al segundo lugar de una nómina cuyo encabezamiento fuera, justamente, una persona intersex; el mecanismo de alternancia (evaluado en la verticalidad de las postulaciones) se vería de imposible implementación bajo las reglas actuales, evidenciándose la limitación que impone el propio marco regulatorio a las facultades exegéticas del juez. [El resaltado no es del original] (TSE, Resolución 8764-E3-2019).

Es decir, la institución política admitió y reconoció la imposibilidad de aplicar alternancia vertical en puestos de elección popular cuando se presenta la candidatura de una persona intersex; ya que la sujeción al ordenamiento le amarró las posibilidades de interpretación, en tanto el legislador únicamente previó la paridad bajo una óptica basada en el sexo registral. Ergo, la identidad de género no es un dato que legalmente produzca efectos más allá de su reconocimiento como lo es para el caso de las cuotas electorales.

Este escenario es una posibilidad muy cercana para todos los países de la región en América Latina: la opinión consultiva, según sea el ordenamiento, orienta a que las naciones incorporen en sus agendas el reconocimiento de la identidad de género autopercibida; empero, este tipo de políticas inclusivas son antinómicas en relación con las intenciones de igualdad de género en materia de elección popular y reivindicación de 


\section{DERECHO ELECTORAL}

espacios políticos para las mujeres. Ahora bien, nótese cómo los universos discursivos están levantando sus cimientos a partir de vicios en el razonamiento de sus idearios.

Las bases del universo discursivo, empleadas desde el plano institucional para el caso de ejemplo, no contemplaron las posibilidades que trascendieran más allá de lo binario (femenino/masculino) $y$, en consecuencia, la narrativa de igualdad se constituye en un mecanismo excluyente para aquellas personas que se encuentren fuera de ese espacio dicotómicamente consensuado.

\section{Apuntes finales}

Mbembe (2006) refiere a Foucault para explicar la aplicación metodológica de la soberanía como droit de glaive (el derecho de matar, de excluir, de desaparecer), que consiste en la ficcionalización de un elemento subjetivo como enemigo. Una ficción: porque esta figura es un imaginario colectivo que echa mano del rasgo sociobiológico particular de un sujeto (raza, orientación sexual, clase, etc.), para el establecimiento de una ruptura relacional y de convivencia entre unos y otros individuos, así como la delimitación de lo que entra y lo que no, en el universo discursivo de la masa.

Tolerantes con garrote es la frase basada en Karl Popper (1945) para referirse a quienes, desde una posición social determinada, aluden a un discurso que es en sí mismo contradictorio en su construcción de razonamiento y que, en la práctica, también resultan ser poco consecuentes con las convicciones que su narrativa sostiene o implica. Este es el caso de la paridad como mecanismo de exclusión: los Gobiernos, los colectivos y los movimientos sociales han comprado las ofertas de un producto político que se ofrece a todas luces como progresista e inclusivo; sin embargo, en el fondo de estas cuestiones e imaginarios, existe un error de razonamiento que introduce la exclusión sistémica de poblaciones marginadas y que, al negárseles el derecho y el acceso a tener una voz en los espacios de decisión no cuentan con un respaldo político que les impulse.

Sea cual sea el sitio de la región latinoamericana, en esta parte del continente predomina un universo discursivo que envuelve narrativas conservadoras y que desplazan institucionalmente a muchas minorías sociales. Construir un basamento que sea coherente en términos de ideas 


\section{DERECHO EIECTORAL}

no ha sido la tendencia de comunicación y opinión pública para América Latina. El ajuste que se requiere no consiste en variar las bases de los razonamientos discursivos que se inyectan en el alma de la masa para ciertas campañas o productos específicos del marketing político; sino, en reformular la manera en que los procesos de formación de opinión pública e imaginarios colectivos se cimientan sobre, precisamente, la construcción de universos discursivos; es decir, que la génesis narrativa implique, necesariamente, una actitud consecuente en convicciones, sin sesgos de razonamiento ni manipulación mediática errada.

El caso de las personas cuya identidad de género autopercibida difiere de la construcción con carácter dicotómico y sus implicaciones de exclusión con respecto al sistema político en Latinoamérica es solo uno de los ejemplos en los que se ha institucionalizado una opinión pública e imaginarios colectivos que se han levantado a partir de la paradoja de la tolerancia y que, de no producirse una reformulación en los cimientos discursivos y socio normativos, reproduce patrones sociales de exclusión sistémica.

\section{REFERENCIAS BIBLIOGRÁFICAS}

Bourdieu, P. (Ene., 1973). La opinión pública no existe. Les Temps modernes, (318), 1292-1309. Recuperado de http://pierrebourdieu.blogspot.com/2006/06/la-opinin-pblica-noexistepierre.html

Castells, M. (2009). Comunicación y poder. Traducción de María Hernández. Madrid: Alianza Editorial.

Crespi, I., Martinez, V. y Mora, A., (2000) El proceso de opinión pública: cómo habla la gente. Barcelona, España: Ariel Comunicación.

Corte Interamericana de Derechos Humanos. (2017). Opinión consultiva oc24/17 de 24 de noviembre de 2017 solicitada por la República de Costa Rica. Identidad de género, e igualdad y no discriminación a parejas del mismo sexo: obligaciones estatales en relación con el cambio de nombre, la identidad de género, y los derechos derivados de un vínculo entre parejas del mismo sexo (interpretación y alcance de los artículos 1.1, 3, 7, 11.2, 13, 17, 18 y 24, en relación con el artículo 1 de la Convención Americana sobre Derechos Humanos). San José. Recuperado de: http://www.corteidh.or.cr/docs/opiniones/seriea_24_esp.pdf 


\section{DERECHO EIECTORAL}

Costa Rica. Tribunal Supremo de Elecciones de Costa Rica. Sentencia n. ${ }^{\circ}$ 8764-E3-2019 de las once horas y treinta minutos del doce de diciembre. Recuperado de: https://www.tse.go.cr/juris/relevantes/8764-E3-2019.html?zoom_highlight=Queer

Espí, A. (Ene.-Jun., 2019). Participación electoral en América Latina: un análisis comparado desde la simultaneidad de las elecciones, 2000-2018. Revista apuntes electorales. (61), 11-38. Recuperado de https://aelectorales.ieem.org.mx/index.php/ae/article/view/722

Held, David. 1997. La democracia y el orden global. Del Estado moderno al gobierno cosmopolita. Barcelona: Paidós.

Hernández, A. (2018). Opresión e interseccionalidad. Revista Internacional de Éticas Aplicadas, (26), 275-284.

Le Bon, G. (2005) Psicología de las masas. Madrid, España: Ediciones Morata.

Mbembe, A. (2006). Necropolítica. Madrid: Editorial Melusina.

Moreno, C. y Rabadánn, R. (2016) Manual de herramientas para la investigación de la opinión pública. Valencia: Tirant lo Blanch.

Neumann, E. (1995) La espiral del silencio. Opinión pública: nuestra piel social. En VV.AA., El nuevo espacio público, pp. 200-210. Barcelona: Gedisa.

Popper, K. (1945). The Open Society and Its Enemies; volume 1: The Spell of Plato. Londres: Routledge.

Programa de las Naciones Unidas para el Desarrollo, Chile (2006). Guía para la transversalización de género en PNUD Chile. Santiago: PNUD. Recuperado de

http://www.cl.undp.org/content/dam/chile/docs/genero/undp_cl_genero_gu ia_tg_2014.pdf

Riorda, M. et al. (2015). El gobernauta latinoamericano: estudio del perfil de los gobernantes latinoamericanos en redes sociales. Washington D. C: Banco Interamericano de Desarrollo. Recuperado de: https://publications.iadb.org/es/publicacion/13880/el-gobernautalatinoamericano-estudio-del-perfil-de-los-gobernantes

Vinuesa, ML. (2008). La opinión pública medida y mediatizada. La comunicación social en la España democrática. Revista Estudios sobre el Mensaje Periodístico, n. ${ }^{0}$ 14, 267-289. Universidad Complutense de Madrid. 